\title{
Dos tendencias en la conformación del nacionalismo estético en Argentina. Las contribuciones de los artistas mendocinos Fernando Fader y Vicente Lahir Estrella al debate sobre el arte nacional
}

\author{
Two trends in the conformation of aesthetic nationalism in Argentina. \\ The contributions of the Mendoza artists Fernando Fader \\ and Vicente Lahir Estrella to the debate on national art \\ Pablo Andrés Chiavazza \\ Facultad de Filosofía y Letras-Instituto de Historia del Arte \\ Universidad Nacional de Cuyo-Argentina \\ pablochiavazza@ffyl.uncu.edu.ar
}

\section{Resumen}

El presente artículo explora, comparativamente, dos tendencias estéticas provinciales que participaron del debate sobre la definición de los alcances y límites del campo artístico en el momento de definición del nacionalismo estético en la Argentina de las primeras décadas del siglo XX. La intención es contraponer los idearios estéticos de dos artistas del interior: Fernando Fader y Vicente Lahir Estrella. El primero erigido en monumento del arte nacional desde su consagración en la capital del país; el segundo prácticamente olvidado a pesar de su importancia en la formación de las primeras instituciones artísticas modernas de la provincia de Mendoza. Sin enfrentarse polémicamente, ambos artistas representaron, dentro del marco delineado por el nacionalismo estético, propuestas divergentes y hasta cierto punto contrapuestas respecto a las formas que debía adoptar el arte argentino, propuestas que se vieron necesariamente atravesadas y estructuradas por las posiciones políticas que asumieron en el contexto de la crisis de la ciudad liberal.

Palabras clave: Arte argentino, Nacionalismo estético, Ideología estética, Fernando Fader, Vicente Lahir Estrella.

\begin{abstract}
This article comparatively explores two provincial aesthetic trends that participated in the debate on the definition of the scope and limits of the artistic field at the time of definition of aesthetic nationalism in Argentina in the first decades of the 20th century. The intention is to contrast the aesthetic ideas of two interior artists: Fernando Fader and Vicente Lahir Estrella. The first erected as a monument of national art since its consecration in the capital of the country; the second practically forgotten despite its importance in the formation of the first modern artistic institutions in the province of Mendoza. Without confronting each other controversially, both artists represented, within the framework outlined by aesthetic nationalism, divergent proposals and to a certain point opposed to the forms that Argentine art should
\end{abstract}


adopt, proposals that were necessarily crossed and structured by the political positions they assumed in the context of the crisis of the liberal city.

Key words: Argentine art, Aesthetic nationalism, Aesthetic ideology, Fernando Fader, Vicente Lahir Estrella.

Recibido: 08 de mayo 2021 - Aceptado: 15 de julio 2021

\section{Introducción: orientaciones hegemónicas en} torno a la definición del nacionalismo estético.

Luego del período de unificación nacional de la Argentina (que podríamos fechar en 1880 con la creación de la Capital Federal) y una vez acordada la unidad entre las oligarquías del interior del país y la de Buenos Aires tras haber acabado con la resistencia de los caudillo provinciales y realizado la campaña contra los indios, es decir, una vez homogeneizado el espacio de la "civilización" tras el disciplinamiento y aniquilación de la "barbarie", el vasto territorio nacional normalizado precisaba no sólo de brazos para trabajarlo con el fin de posibilitar su inserción efectiva en el mercado mundial, sino además de representaciones que propiciara una identificación común. Eduardo Grüner lo sintetizó del siguiente modo:

la representación de una "identidad nacional" en la que todos los súbditos de un Estado pudieran reconocerse simbólicamente en una cultura, una lengua y una tradición histórica comunes (además de coexistir físicamente en un territorio muchas veces artificialmente delimitado) fue desde el principio un instrumento ideológico de primera importancia. Y, desde el principio, las imágenes y la lengua -por lo tanto el arte y la literatura, entendidos como institucionesconstituyeron elementos decisivos de dicha construcción. (Grüner, 2004: 2)

La representación hegemónica del proceso civilizatorio nacional sufrió varios desplazamientos entre la euforia de 1880 y las celebraciones del centenario de la revolución de mayo en 1910. Entre ellos, probablemente el de mayor importancia fue la inversión del postulado de Sarmiento que identificaba el desarrollo urbano como signo clave de civilización, contra la barbarie caracterizada por la ruralidad y el caudillismo del interior del país. Esta oposición entre civilización y barbarie operó, desde su formulación durante el exilio de Sarmiento en Chile en 1845, como eje ordenador del proyecto de construcción de la nación argentina desde la óptica liberal. Y la oligarquía triunfante de 1880 construiría la ciudad bajo este paradigma.

Sin embargo, tal como indicamos, poco tiempo después se produjo una inversión de este paradigma, cuando la política inmigratoria puesta en marcha para poblar el país se tradujo en un crecimiento urbano notable que de inmediato comenzó a mostrar sus contradicciones. La ciudad, concebida como máquina civilizatoria, adquiría 
paulatinamente perfiles desagradables para la oligarquía nacional en función de los comportamientos y demandas sociales y políticos crecientes de los sectores plebeyos que arribaban al país. Para la oligarquía en su conjunto, tal situación se experimentaba como un verdadero arribismo o, tomando la terminología que se aplicaba en la época, como una "invasión” (Viñas, 2014: 93). A esta idea se sumaba el temor a la "contaminación", es decir, a la mezcla que daría por resultado la pérdida de las tradiciones que sustentaban el imaginario cultural de quienes dirigían los destinos del país.

Lo que estaba en juego era entonces el papel directriz de la élite gobernante, lo cual hacía perentorio dar impulso a un proceso de nacionalización orientado a integrar a las masas inmigrantes en una identidad común (Terán, 2015) en un marco en que la representación idealizada de Buenos Aires como la "Atenas del Plata" daba paso a la más confusa imagen de la "Babel del Plata" (Viñas, 2013). Fue entonces que el interior del país comenzó a cobrar una nueva significación, y los intelectuales, artistas y escritores, sobre la base de la organización de las instituciones artísticas y literarias, emprendieron la tarea de elaborar una tradición cultural que colocaba al campo y a las provincias, con a sus paisajes y tipos humanos autóctonos, con su deferencia y valores tradicionales, como refugio del auténtico ser nacional.

Podría decirse que fueron los intelectuales provincianos que alcanzaron éxito y resonancia en Buenos Aires quienes mejor articularon ese nacionalismo estético que se apuntaló en torno al centenario de la revolución de mayo. El escritor Manuel Gálvez con "El diario de Gabriel Quiroga” donde aseguraba que la salvación de la nación se encontraba en las provincias; Joaquín V. González con “Mis Montañas”, que según relata le enseñaron a mirar al biógrafo de Fader, Lascano González; Ricardo Rojas con "La restauración nacionalista" pero sobre todo con su "Eurindia", en la que define una hermenéutica del proceso cultural nacional que, en una suerte de inversión mecánica de la vieja dicotomía sarmientina entre civilización y barbarie, oponía las categorías positiva de "indianismo" y negativa de "exotismo".

Según su representación del proceso histórico, la cultura nacional había estado signada por una serie de vaivenes entre estos dos términos: nativos vencidos por españoles; luego gauchos americanos que se imponen al colono español; y finalmente gauchos argentinos vencidos por inmigrantes europeos que lleva a una nueva síntesis en que serán vencidos los “mercaderes inmigrados" por los “artistas autóctonos", aunque en este proceso, para Rojas no debe incurrirse en la "xenofobia marcial" que cada vez se hacía más patente en el escenario político nacional (Rojas, 1951).

En ese marco se inscribe el pensamiento y a obra de otro provinciano, el artista Fernando Fader, sobre los cuales queremos detenernos, puesto que estructuran de modo muy claro las inquietudes nacionalistas en el campo de las ideologías estéticas y, por lo tanto, de las políticas de representación en torno a lo nacional. A pesar de que había nacido en Burdeos en 1882 y arribado con su familia a la provincia de Mendoza en 1886, Fader siempre se autoidentificó como mendocino[1]. Luego de realizar estudios en Munich, regresa a la provincia y poco tiempo después se traslada a Buenos Aires, 
donde inmediatamente obtuvo reconocimiento, siendo consagrado por Cupertino del Campo (pintor y futuro director del Museo Nacional de Bellas Artes) mediante un artículo aparecido en diario La Nación titulado "Un pintor argentino" en el que sostenía que "no hay otro pintor en el país capaz de exhibir una obra semejante... [Ante su obra] el crítico se desarma. Está en presencia de un gran artista argentino, que hace honor a su patria" (Gutiérrez Viñuales, 1998: 31). Tal reconocimiento no hizo difícil el ingreso del artista a los círculos de intelectuales nacionalistas que buscaban en el interior del país una respuesta a la crisis de la ciudad liberal.

Este reconocimiento en el campo artístico e intelectual dio lugar a que Fader desarrollara sus ideas estéticas en una serie de manuscritos que han llegado a nuestros días y que nos permiten apreciar sus concepciones a propósito de quiénes están autorizados y quienes no a elaborar las representaciones de la nación. En uno de esos manuscritos Fader sostuvo que:

[...] más que nunca puede hoy apreciarse lo peligroso que en movimientos intelectuales o artísticos es la participación de la muchedumbre. Y como una lección [...] recogemos la enseñanza de la necesidad de conversar a todo trance el ideal individual, en contraposición al colectivo. Esta idea debe ser inculcada a todo elemento artístico desde un principio. La necesidad de concentrarse retraído de todo contacto intelectual con los mediocres, viene a ser cuestión vital para un temperamento personal en arte. Nada más dañino que los mediocres porque son vulgares y siendo vulgares se oponen intensamente a la idea artística. Si los artistas personales salen de la muchedumbre, ésta no está autorizada para ver en ellos una expresión de sus hábitos o de sus ideales. Ni nunca podría exigir a un elegido que trance por su origen con lo vulgar o con lo mediocre. (Cippolini, 2011: 58)

Para Fader el ideal del artista “...no debe ser una idea de las que llenan el oído de los mediocres, que es la muchedumbre del arte, los proletarios. No debe aceptar un ideal colectivo porque no existe la belleza como idea de la muchedumbre, ni existe la verdad colectiva sino una verdad individual." (Gutiérrez Viñuales, 1998: 263). Es quizás en la asociación de los términos empleados por el artista donde mejor puede apreciarse el modo en que sus concepciones estéticas se encuentran atravesadas por la conflictividad política y social de principios de siglo desde la óptica de la clase dominante. El verdadero artista es aquél cuya posición intelectual se encuentra apartada de los ideales colectivos, a los que asocia con lo mediocre, lo vulgar, la muchedumbre, la plebe, el proletariado. En síntesis, el artista es aquel que no pertenece a las clases populares, incluso si ha surgido de ellas. La excluyente formulación de Fader intentaba clausurar la contaminación de las representaciones nacionales por las narrativas e imágenes producidas por el "populacho". Y en este sentido, las ideas del artista daban forma en el campo de las ideologías estéticas a las inquietudes de una oligarquía temerosa ante el avance de los sectores populares sobre la ciudad moderna. 
Pero probablemente el elemento clave de su pensamiento estético, a través del cual intentaba imprimir un cierre definitivo a las aspiraciones plebeyas de articular sus propias representaciones, se encuentre en su definición a propósito de qué es lo que define a un artista. Siguiendo el hilo de la cita anterior, Fader sostiene que:

No hay duda de que convendría llevar la educación [artística] de la muchedumbre a un nivel superior, con tal de asegurar que los elegidos saldrían de una mayor potencia intelectual, pero tampoco hay duda de que esta educación, aun transmitida por generaciones, no modificaría el estado que a todo arte se opone: la vulgaridad. Puesto que ella es la característica imborrable de la plebe por bien educada, por ilustrada que fuera, porque ni con lo uno ni con lo otro se llegaría a nivelar lo que no puede nivelarse: los instintos.

Además ninguna ilustración, ninguna educación podrá inculcar sentimientos que no están porque son sentimientos inherentes a organismos más complicados, y por consiguiente más es espirituales; ergo, aptos para producir arte en determinadas condiciones. Y los que de la plebe salen con este organismo complicado, están predestinados a no pertenecer más a ella, desligados totalmente por leyes superiores". (Cippolini, 2011: 58)

Ya lo había sostenido en oportunidad de su primera exposición consagratoria en Buenos Aires: “...la base de la obra artística es cierto sentido especial del artista para sentir la naturaleza", dijo a la prensa en esa ocasión (Gutiérrez Viñuales, 1998: 26). La “cosa real”, el tema o el argumento literario no es lo que define al artista, ni siquiera la destreza técnica adquirida en el proceso de formación, pues éstos no son más que medios para alcanzar la verdadera finalidad pictórica. Lo que importa es la verdad del objeto revelada por a la sensibilidad del artista. $O$, dicho de otro modo: lo que importa es la verdad de la nación revelada a la percepción especial del artista. En Fader este argumento se encuentra atravesado por una concepción según la cual dicha sensibilidad artística no sólo constituye el punto de partida y fundamento esencial de toda verdadera obra de arte, sino que además se encuentra determinada biológicamente.

Aquí el lenguaje empleado por el artista es el del darwinismo social, el mismo que surge de la perspectiva reduccionista que Herbert Spencer practicó al trasladar la teoría de la selección y variabilidad de Charles Darwin a la explicación de la vida social. Una perspectiva organicista que servía de patrón interpretativo de la realidad histórica a una oligarquía liberal nacionalista en trance de perder su hegemonía política (Vallejo y Miranda, 2004). Sólo los individuos mejor dotados por la naturaleza, aquellos mejor adaptados, se encuentran en condiciones de producir arte, toda vez que es de la complejidad biológica, orgánica, de la cual se desprende una mayor sensibilidad y espiritualidad. Dicha complejidad, el artista lo deja claro, no se encuentra en los individuos pertenecientes a la plebe.

Esto lleva a Fader a sostener que "la relativa novedad del ideal colectivo ha producido forzosamente 
un exceso de expresiones artísticas novedosas, falsas en su gran mayoría porque son derivadas de un concepto de pensamiento más bien que de sentimiento o, en una palabra, expresiones experimentales; carecen de la base sentimental." (Gutiérrez Viñuales, 1998: 256). Por lo tanto, no es la educación artística (mediante la cual sólo es posible adquirir una formación técnica) la que impulsará un verdadero arte nacional, ya que esa educación, desde la perspectiva del artista, no puede proporcionar lo que la naturaleza no ha otorgado, a saber, la sensibilidad adecuada para producir arte. Por lo tanto, dicho arte sólo puede surgir de un círculo restringido de individuos desligados de la plebe por "leyes superiores".

Resulta en este punto pertinente observar, tal como lo ha hecho Pierre Bourdieu, que "una estética que confiere a la manera de percibir la supremacía sobre la cosa percibida proporciona recursos inagotables para la búsqueda de la distinción: en efecto, tiende a operar (entre quienes poseen el modo adecuado y quienes no disponen de tiempo libre o medios para fijar en la obra de arte la mirada "depurada" y "desinteresada" que ella exige) una diferencia tajante, de todo o nada, que la ilusión del a priori -otro nombre de la inconsciencia de la historia- tiende a considerar una distinción de esencia o de naturaleza" (Bourdieu, 2010: 72). De este modo, el énfasis puesto en la determinación biológica de la percepción artística (una forma de "distinción de naturaleza"), cierra el círculo de una aristocracia artística que constituye, a ojos de Fernando Fader, el núcleo indispensable para la conformación de un auténtico arte nacional.
Es indudable que estas ideas estéticas se encuentran signadas por la posición política[2] que Fader asume respecto de las profundas transformaciones operadas bajo el influjo de un proceso de modernización que modificaba fuertemente la fisonomía del país, poniendo en riesgo los privilegios de una élite que veía amenazada su posición por el avance de los movimientos colectivos (democráticos, socialistas, sindicalistas). Debemos recordar que en el contexto en que Fernando Fader formula y desarrolla estas concepciones, se encuentran en pleno desarrollo formas de arte vinculadas a los sectores populares y a la vida suburbana. De los márgenes de la ciudad (el barrio, el arrabal, el conventillo) han surgido otras formas estéticas cuyo alcance popular confronta la hegemonía artística e intelectual de la élite. Pensemos, por ejemplo, que en la década del 10 se encuentra el origen de la "Escuela de Barracas", integrada por un conjunto de artistas que habitaban el arrabal porteño y que bien pueden ser calificados-aunque sin la intención peyorativa que daba a la frase Fader- como “proletariado artístico”.

Del grupo de Barracas surgiría en los años 20 el conjunto denominado "Artistas del Pueblo" integrado por José Arato, Adolfo Bellocq, Guillermo Facio Hebequer, Agustín Riganelli y Abraham Vigo[3]. Ellos mismos surgidos de los sectores populares y trabajadores, orientaron su trabajo artístico a "interpretar la conciencia del pueblo" y denunciar críticamente la miseria en la que se veía sumida la existencia en los bordes de la gran urbe (Muñoz, 2008). Este proceso de democratización y plebeyización cultural, mediante el cual los sectores populares introducen nuevas voces en el escenario social, es el que inquieta a Fader, 
pues sólo acierta a ver en él un movimiento de "mediocres [que no son más que la] expresión fiel de los peores instintos de la plebe. Los perturbadores por excelencia, vanidosos en extremo y una amenaza constante por su pretensión de igualdad, inadmisible en arte" (Cippolini, 2011). Y es ante la pretensión democrática de los sectores populares que conduce sus ideas hacia una posición estético-política aristocrática, excluyente y biologicista, pues para el artista "no hubo guerrero sin ideal político, ni sacerdote, ni filósofo, ni artista. [...] considerándolos como superiores dentro de su raza y de su época, tendían al mismo fin: hacer primar su yo o sea su ideal propio sobre la colectividad" (Cippolini, 2011: 71).

\section{La democratización estética en la perspectiva nacionalista de Vicente Lahir Estrella.}

Contemporáneamente al ascenso de Fernando Fader como exponente destacado del arte pictórico nacional y referente indiscutido del arte mendocino, otras posiciones disputarán el sentido y la función de la producción artística en el medio nacional y de la provincia de Mendoza.

Una personalidad clave, pero relativamente olvidada, fue la del artista y docente mendocino Vicente Lahir Estrella. Fue fundador de la primera Academia de Dibujo, Pintura y Modelado de la provincia, que funcionó entre 1915 y 1920, además de crear la Asociación de Extensión de Actividades Artísticas al Aire Libre, de la cual dependía la Escuela de Dibujo al Aire Libre (1933) y participar como fundador de la Academia Provincial de Bellas Artes y Escuela de Artes Decorativas e Industriales de Mendoza (1933), todas instituciones clave en las cuales impartieron clases gratuitas de arte para todas las edades y donde se formaron los primeros artistas modernos locales.

El proyecto encarado por Estrella puede sintetizarse en lo que definió como "educación estética popular". Para Estrella, la enseñanza de las artes era, fundamentalmente, conocimiento de la naturaleza. La idea que sostenía el artista era que la educación estética y la práctica artística debían proporcionarse a toda la población. No se trataba de una formación orientada exclusivamente a generar artistas, sino a posibilitar que toda la comunidad, desde la infancia, tomara contacto con el entorno natural con el fin de asimilar sus características como parte del proceso de formación de ciudadanía. Ciertamente se trató de un proceso de normalización, pero a diferencia de las posiciones asumidas por la estética aristocrática, no resultaba de un proceso excluyente.

El dibujo inculcado desde la infancia obligaba a la observación cuidadosa y al amor por el paisaje, conduciendo a un proceso de apropiación de sus características que son-bajo la óptica de Estrellalas que determinan la cultura regional, provincial. Esto cumplía con una función social y cultural fundamental: la de incorporar a los inmigrantes e hijos de inmigrantes al orden nacional a través de lo regional (cuyo sentido debía buscarse en el entorno natural). Estrella se refiere en varios de sus textos a predisposiciones biológicas hereditarias que no pueden modificarse, pero sí confía en que la enseñanza puede apaciguar esa "herencia racial" transmitida de padres a hijos y que termina obrando en estos "subconscientemente", 
impidiendo de ese modo configurar una cultura propia (Chiavazza, 2010). En 1938 escribía:

[...] estamos estructurando nuestra característica regional. No es que pretendamos eliminar tendencias que obran subconscientemente en la mentalidad del niño, no porque sería una utopía ir en contra de las leyes biológicas de la evolución individual. Pero si hacer que los factores influyentes, telúricos y del medio en que el niño vive, mantengan su supremacía sobre aquellos otros, enfrentándolo a la naturaleza de la que forma parte físicamente. La montaña y la llanura nos han dado dos hombres de psicología diametralmente opuesta. Eso pretendemos, que la visión de las cosas y el paisaje que vive, sea su punto de referencia para sus concepciones. (Estrella, 1963)

El artista apoya sus argumentos en los estudios de la psicóloga infantil Telma Reca, difundidos en esos años por la famosa revista "Caras y Caretas". $Y$ esto constituye un viraje fundamental con respecto a las posiciones biologicistas propias del darwinismo social, al introducir el factor histórico como una de las variables en la conformación de la personalidad de los sujetos. Ciertamente no abandona la interpretación evolutiva del proceso social, pero presiona contra esta concepción al introducir la posibilidad-lecturas psicológicas mediante- de que aquella determinación natural puede ser modificada a través de la cultura. Estrella cita en extenso los comentarios de Reca en el mismo artículo de 1938:
El niño como personalidad, es un producto de la acción combinada de la herencia y del medio ambiente [...] Psíquica, como físicamente, el niño de un día de edad es el niño que nació más un día de vida; el niño de hoy, cualquiera edad que él tenga, [es] el niño que nació más todo su pasado. Y aquel día de vida y este pasado implican, no exclusivo crecimiento natural, sino experiencias, emociones, sentimientos, conocimiento, hábitos adquiridos, en una palabra, integración de la personalidad en virtud del desarrollo venido de adentro, como ley de la vida y por obra y acción del medio ejercida desde afuera. (Estrella, 1953)

Como vemos, esta visión configura una posición alternativa al darwinismo social patente en las concepciones de Fader, pues si bien reconoce la herencia biológica como condición en la formación del carácter del sujeto, introduce la posibilidad - por vía de los argumentos de Reca-que las experiencias históricas "mantengan su supremacía" sobre ella. De modo que la educación artística no sólo es posible sino deseable como instrumento de formación de nuestro carácter cultural regional y nacional y como punto de partida para el surgimiento de nuevos artistas de la "masa aluvial" inmigratoria.

La educación estética popular impulsada por Estrella a través de la Escuela de Dibujo al Aire Libre constituyó, sin dudas, uno de los pilares del campo artístico moderno local. Probablemente una de las consecuencias más notorias del temprano impulso dado por lasideas y lasprácticas este artista sea la generación de las condiciones y relaciones 
propicias para la organización institucional de las artes en nuestro medio. Puesto que debemos considerar que la formación estética extendida a toda la población permitía la adquisición de los conocimientos sobre las convenciones plásticas, generando así en el sujeto receptor las disposiciones adecuadas para la interpretación de las obras de arte. Las ideas de Estrella, vinculadas todavía en los años 30 a las concepciones evolucionistas y positivistas en franca declinación, darán lugar, sin embargo, a otras prácticas culturales y a otras soluciones formales a cargo de las formaciones artísticas sucesivas.

Lo que resulta importante destacar entonces es precisamente la generación de estas condiciones a partir de una concepción que permitió, sin dudas, la participación en asuntos artísticos de los sectores populares.

\section{A modo de conclusión}

Hemos contrapuesto estas dos figuras porque fueron ellas las que condensaron y elaboraron de modo coherente respuestas culturales específicas desde la situación periférica y provincial a ciertos conflictos desencadenados por los procesos de modernización social actuantes a lo largo del primer tercio del siglo XX, contribuyendo a dar forma, de esa manera, al campo artístico local a través de la determinación de las funciones del arte en la sociedad de su tiempo (en Fader como instrumento de distinción y en Estrella corno instrumento de integración) en el marco de la formulación de lo que hemos definido como nacionalismo estético. Si bien ambos artistas no se enfrentaron en debate ni generaron, hasta donde sabernos, controversia alguna, sus posiciones marcaron claramente dos tendencias en el temprano proceso de formación del campo artístico moderno local que tendrían consecuencias en las sucesivas generaciones de artistas mendocinos, en las formas de su organización y en los modos en que dieron respuesta, bajo las circunstancias que debieron afrontar, a las condiciones históricas y sociales desde la práctica artística.

Llegados a este punto nos sentimos tentados a pensar estas posturas contrapuestas como prolongaciones, modificadas, bajo nuevas formas y conceptualizaciones de la tan mentada dicotomía decimonónica entre "Civilización y Barbarie", como si ésta operara a modo de un patrón cultural rastreable desde su formulación hasta nuestros días bajo la forma de otras categorías cuya función hubiese sido la de estructurar posiciones socio-culturales en conflicto (culto-popular, tradicional-moderno, global-local, centro-periferia). En el caso que hemos tomado la contraposición se evidencia en una posición aristocrática enfrentada a una más bien democrática. Creemos que no carecería de interés que la historia del arte, en cuanto disciplina, abordara esta problemática de nuestra historia cultural observando el modo en que estas y otras categorías han operado en los conflictos del campo artístico local, prestando especial atención a cómo éstos constituyeron formas de estructurar problemáticas sociales e históricas más amplias. 


\section{Referencias citadas}

Altamirano, C. (2013): Intelectuales. Notas de investigación sobre una tribu inquieta, Buenos Aires, Argentina, Siglo Veintiuno Editores.

Bourdieu, P. (2010): El sentido social del gusto. Elementos para una sociología de la cultura, Buenos Aires, Argentina, Siglo Veintiuno Editores.

Chiavazza, P. (2013): Una academia sin par. 80 años de la Academia Provincial de Bellas Artes. 80 aniversario de la Academia Provincial de Bellas Artes de Mendoza, Mendoza, Municipalidad de la Ciudad de Mendoza.

Chiavazza, P. (2010): “Vicente Lahir Estrella y su rol en la construcción del moderno campo artístico mendocino”, en Distéfano, G., O. Zalazar, M. D Márquez y P. Chiavazza, El ojo de la época. 4 ensayos para una muestra, Mendoza, Fundación Gutenberg, pp. 51-62.

Cippolini, R. (2011): Manifiestos argentinos: Políticas de lovisual 1900-2000, Buenos Aires, Adriana Hidalgo Editora.

Estrella, V. L. (1963): 30 años de experiencias y realizaciones al servicio de la educación estética popular 1933-1963, Mendoza, Editorial Surco.

Estrella, V. L. (sf): Memorias, Mendoza, Inédito.

Grüner, E. (2004): “El conflicto de la(s) identidad(es) y el debate de la representación. La relación entre la historia del arte y la crisis del político en una teoría crítica de la cultura”, La Puerta FBA, 1, pp.58-68.
Gutiérrez Viñuales, R. (1998): Fernando Fader. Obray pensamiento de un pintor argentino. Santa Fe, Instituto de América, CEDODAL.

Muñoz, M.Á. (2008): Los artistas del pueblo 1920-1930, Buenos Aires, Fundación OSDE.

Rojas, R. (1951): Eurindia. Ensayo de estética sobre las culturas americanas, Buenos Aires, Editorial Losada.

Terán, O. (2015): Historia de las ideas en la Argentina. Diez lecciones iniciales, 1810-1980, Buenos Aires, Siglo Veintiuno Editores.

Vallejo, G. y Miranda, M. (2004): “Evolución y revolución: explicaciones biológicas de utopías sociales”, en H. E. Biagini, El pensamiento alternativo en la Argentina del siglo XX. Identidad, utopía, integración (1900-1930) Vol. I,), Buenos Aires, Editorial Biblos, pp. 403-417.

Viñas, D. (2014): De los montoneros a los anarquistas, Buenos Aires, Santiago Arcos Editor.

Viñas, D. (2013): Indios, ejército y frontera, Buenos Aires, Santiago Arcos Editor.

Viñas, D. (1973): Literatura argentina y realidadpolítica. La crisis de la ciudad liberal, Buenos Aires, Ediciones Siglo Veinte.

\section{Notas}

[1] Al menos desde el momento en que ingresa en la vida pública nacional como un pintor reconocido, cosa que ocurre hacia 1905, en cada oportunidad que se le interrogó sobre su origen indicaba que había nacido en 
Mendoza. Probablemente esta identificación guardaba alguna relación con la ideología nacionalista reactiva al proceso inmigratorio

[2] Hemos de insistir en aclarar que cuando nos referimos a la posición política del artista no estamos pensando exclusivamente en sus preferencias partidarias, sino más bien en el modo en que interviene como intelectual en los problemas de la ciudad, de la "polis", definiendo sus posiciones con respecto a otras en el contexto de disputas en torno a la función social del arte.

[3] Abraham Vigo vivirá en Mendoza entre 1939 y 1947, convirtiéndose una figura muy influyente en el ambiente artístico al propiciar la agremiación de los artistas locales y al formar a algunos jóvenes estudiantes de la Academia Provincial de Bellas Artes en las técnicas del grabado. 